use the same threads up to $80 \mathrm{~mm}$ diameter.

In order to assure the free circulation of engineering components and subassemblies in the European Common Market, the UK government - led by Harold Wilson announced in May 1965 that British industry would abandon the inch within ten years and adopt ISO metric standards. The first attempt to produce a British engine to metric standards was already in progress at Leyland Motors with the Leyland 500 engine. However, this was marketed in continental Europe only in the Leyland National bus, whose full metrication was never completed: it incorporated four different screw-thread standards and was impossible to manage in European workshops.

British Leyland vehicles failed to attract continental dealers because the inch was already alien in mainland Europe - it had actually been outlawed in mechanical engineering in Germany during the 1930s. It remained only in water- and gas-pipes, and in certain items imported from the United States.

Inch threads had no future in Europe, but the planned conversion of British engineering factories did not occur. As a result, the UK's non-metric products were rejected by Europe as a nuisance.

It was the abandonment of Wilson's metrication programme, along with deficient marketing, that caused the stagnation of British Leyland and so many other engineering-based companies in the United Kingdom. The economic effects of Britain's failure to adopt the metric system on schedule have never been quantified. But the recent loss of the $\$ 125$ million NASA Mars Orbiter probe emphasizes the vast sums of money that can be lost through the unfamiliarity of the average UK or US technocrat with metric units.

Michael T. Knowles

11 Powlett Court, Bath BA2 6QJ, UK

\section{Instrument's ability to do the job is NASA's priority}

Sir - In your News profile article "Sky's the limit as teams bid for NASA Project" (Nature 403, 587; 2000), Colin Macilwain implies that NASA administrator Daniel Goldin's professed enthusiasm for particle physics detector technologies would be a factor in the selection of one of two competing instruments for the Gammaray Large Area Space Telescope Mission. (High-energy gamma-ray instrumentation has always drawn heavily from techniques developed for high-energy physics studies.) There is the further implication that contributions to the cost might also provide an advantage.

Although the winning team, from Stan- ford, contains particle physicists sponsored by the Department of Energy, this had no direct bearing on the selection. It is NASA's policy to select instruments for its missions through a peer-review process that evaluates first and foremost the proposed science and the proposed instrument's ability to achieve that science. There are other factors, but these do not include the participation of other partners, either foreign or domestic, unless they can help the team achieve their science goals.

Incidentally, your News profile stated that the competing instrument was from NASA's Marshall Space Flight Center (MSFC). Although MSFC did participate, along with several other institutions, the principal investigator was from the University of Alabama in Huntsville, and the proposal was submitted through the university. The selected instrument also included a team from NASA's Goddard Space Flight Center, as well as several other institutions, both domestic and foreign.

Donald A. Kniffen

NASA Headquarters, Office of Space Science, Research Program Management Division, Washington DC 20546, USA

\section{Putting marine mammals back in the mainstream}

Sir-I read with interest Vaclav Smil's Millennium Essay ${ }^{1}$, in which he describes the general importance to bioenergetics of Max Kleiber's studies on the scaling relationship of metabolic rate with body mass in animals. Across 18 orders of magnitude from unicellular organisms to whales, it seems metabolic rate is proportional to body mass raised to the power of 0.75 ; the so-called three-quarters rule, exemplified by the wellknown mouse-to-elephant curve.

Smil gives the example of marine mammals as species whose metabolic rates lie outside this relationship because, apparently, seals and whales have basal metabolic rates (BMR) about twice as high as those of other animals their size, which illustrates their environmental specialization for thermoregulation in cold water. However, there is evidence that is inconsistent with this view ${ }^{2}$.

The perception that pinnipeds (seals, sea lions, fur seals and walrus) and cetaceans (whales, dolphins and porpoises) have BMRs twice as high as similar sized animals is an idea that has been widely accepted for decades. It primarily arises from comparisons of marine with terrestrial mammal data.

In his studies, Kleiber was very specific about the conditions under which BMR measurements should be made, in a bid to reduce variance between comparisons of basal rates in animals of different size and from different taxonomic groups.

(Measurements should be made on mature animals in a post-absorptive state, nonreproductive, at thermoneutral ambient temperatures, and without abnormal activity $^{2}$.) For these reasons, Kleiber rejected the use of the two determinations for marine mammal BMR available to him when preparing his original paper.

Nevertheless, published BMR data for marine mammals often have not conformed to these criteria, but have been included in comparative analyses with data that do. This has led to the widely held view that marine mammals have higher BMRs and that they are therefore not 'normal' mammals.

In the analysis by Lavigne et al. ${ }^{2}$, where data from studies on seals and whales were excluded when determinations did not fulfil Kleiber's criteria, it appears that metabolic rates of marine mammals were indistinguishable from those predicted for other mammals under similar conditions. In support of this conclusion, the best available data on minke whale

(Baleanoptera acutorostrata) metabolic rates, determined from field tracking studies and heat loss determinations ${ }^{3}$, give a value at zero swimming speed only 17 per cent greater than the BMR value predicted from Kleiber's general equation.

Clearly, these studies suggest that Kleiber's relationship applies just as well to marine mammals as to terrestrial species.

\section{David W. Sims}

Department of Zoology, University of Aberdeen, Aberdeen AB24 2TZ, UK

1. Nature 403, 597 (2000).

2. Lavigne, D. M. et al. Can. J. Zool. 64, 279-284 (1986).

3. Blix, A. S. \& Folkow, L. P. Acta Physiol. Scand. 153, 61-66 (1995).

\section{Persian role in flowering} of Islamic science

Sir - Giovanni Bignami in his Millennium Essay (Nature 404, 227; 2000) qualified two Persian thinkers, Avicenna and Omar Khayyàm, as belonging to the Arabic world. Occidental writers frequently take "Muslim" to mean "Arab" and consider Islamic culture to be Arabic. Yet even 1,000 years ago the Islamic world was composed of people of quite different origins. Many of the thinkers who participated in the blossoming of science at that period were in fact Persians and not Arabs. Saadi Khochbin

INSERM U309, Institut Albert Bonniot, 38706 La Tronche Cedex, France

Erratum The number of signatories to the letter "Distinguished scientists back Germany's DFG..." (Nature 404, 922; 2000) is 1,641 - not 1,164 , as stated in the correspondence. Nature apologizes for this error. 
the middle of the twenty-first century the world is going to face a food crisis, and that agriculture will consequently put increased pressure on wildlife habitats.

In 1998, the UK Institute of Biology and six affiliated societies (whose specialist interests range from agricultural production to ecological conservation) produced a report on the social and ethical aspects of GM crops ${ }^{2}$. We cited half a dozen indicators of the forthcoming shortfall in global food supply, including the following. Forty per cent of terrestrial primary productivity is already managed by humanity. The trend for the past 15 years has been a reduction in grain production per capita. Global seafish catches have been in steady decline since 1990 because of over-fishing. World carry-over stocks of grain are declining from one year to the next. The grain harvest area per person has been declining since the late 1970 s, owing to increasing population, growth in industry and desertification.

The increasing consumption of meat in the rich nations has put more pressure on the poor, although reversing this trend alone (even if it were realistic) would not counter the pressures caused by a population increase of 40 to 80 per cent over the next four decades. The world shows no sign of turning vegetarian. Although I am sympathetic to Latham's conclusion that "what is missing is the 'purchasing power' of the poor", the evidence is that when the poor become a little richer they eat more meat.

Given that agricultural inefficiencies and global inequalities are bound, sadly, to continue, it is likely that genetic modification where appropriate will make a significant contribution to human well-being and to that of other species.

\section{Jonathan Cowie}

Institute of Biology, 20-22 Queensberry Place, London SW7 2DZ, UK

1. Nature 404, 222 (2000).

2. GM Crops: The Social and Ethical Issues (Institute of Biology, 1998). www.iob.org/gmocrops.html

\section{Distinguished scientists back Germany's DFG...}

Sir - Your recent News report "German research agency stifles creativity" (Nature 404, 217; 2000) gives a negative and incorrect impression of the Deutsche Forschungsgemeinschaft (DFG).

Nature claims that DFG's inability to assess novel research areas and interdisciplinary research areas threatens career opportunities, especially for young researchers. The cases mentioned in the Nature report, however, are neither representative nor described in an unbiased manner.
Typically, the reviewing process of the DFG takes less than six months and involves a large number of scientists from foreign and German institutions and from senior as well as junior ranks. Every attempt is made to support the best and the most innovative scientific proposals. In fact, time and again highrisk proposals are funded that, for example, would have no better chance of support from the US National Institutes of Health.

Of course, no system is free of errors, and occasional undeserved negative judgements may be made. However, continual efforts are made to improve the system. Overall, we are impressed by the flexibility of the DFG, its unbiased support for creative, high-quality research and its programmes for young scientists and interdisciplinary research even at times when its budget is tight.

At this juncture, our most urgent concern is to convince politicians to increase funding to the DFG significantly. This is particularly important for the support of young scientists. We are very proud of the DFG as a self-governing body of the German scientific community and we believe it to be, by any standards, one of the best scientific funding agencies. Reinhard Jahn

Max Planck Institute for Biophysical

Chemistry, Am Fassberg, D-37077

Göttingen, Germany

rjahn@gwdg.de

Other signatories of this letter:

August Böck Ludwig-Maximilians-Universität München

Klaus M. Breiner Emmy-Noether-Fellow, ETH Zürich

Karin D. Breunig Universität Halle-Wittenberg

Herman Bujard Universität Heidelberg

José Campos-Ortega Universität zu Köln

Detlev Ganten Max-Delbrück-Zentum, Berlin-Buch

Ingrid Grummt Deutsches Krebsforschungszentrum, Heidelberg

Peter Gruss Max-Planck-Institut für biophysikalische Chemie, Göttingen

Christo Goridis CNRS, Marseille

Robert Huber Max-Planck-Institut für Biochemie, München Michael Hoch Gerhard-Hess-Fellow, Universität Bonn

Herbert Jäckle Max-Planck-Institut für biophysikalische Chemie, Göttingen

Regine Kahmann Ludwig-Maximilians-Universität München

Claudia Koch-Brandt Universität Mainz

Maria Leptin Universität zu Köln

Hartmut Michel Max-Planck-Institut für Biophysik, Frankfurt Angelika Noegel Universität zu Köln

Erwin Neher Max-Planck-Institut für biophysikalische Chemie, Göttingen

Christiane Nüsslein-Volhard Max-Planck-Institut für

Entwicklungsbiologie, Tübingen

Nikolaus Pfanner Universität Freiburg

Konrad Sandhoff Universität Bonn

Astrid Schoen Heisenberg fellow, Universität Würzburg

Petra Schwille Biofuture junior group, Göttingen

Kai Simons Max-Planck-Institut für molekulare Zellbiologie und Genetik, Dresden

Eberhart Zrenner Universität Tübingen

Signed on behalf of 1,164 other biomedical scientists. The full list of names is available from $R$. J.

\section{... . but young researchers feel disillusioned}

Sir - Your recent News report "German research agency stifles creativity" (Nature 404, 217; 2000) gives a negative impression of the Deutsche Forschungsgemeinschaft (DFG) - but one that is, in our experience at least, correct.

Nature claims that the process threatens young researchers' career opportunities in particular. Our last four applications for grants in the area of environmental toxicology (mechanisms of microcystin toxicity in the aquatic environment) were rejected, after an average delay of 10-12 months, as "irrelevant" or "dealing with non-existent problems". We did, fortunately, receive support for a similar grant from the European Union; the results of these studies have been or will be published this year, and they form the basis of an EU patent application.

The referees of our unsuccessful DFG applications did not seem, to us, to be upto-date in their knowledge of the topic, or they had little understanding of environmental toxicology. Indeed, the comments we received from the DFG made us wonder whether the referees had even read the grant. They were so contradictory of each other as to provide us with no constructive advice on how to improve the application. The upshot was that, while we were able to demonstrate that our proposed research could be done, and was publishable in peer-reviewed journals, it was not considered fundable by the DFG. This kind of outcome may not seem devastating to seasoned scientists with established careers. But it impedes the careers of young researchers dependent on DFG funding within Germany, and is demotivating.

A better approach would be for grants to be sent out for review internationally; for referees' comments to be sent to the applicants in their original form, not rewritten by DFG to maintain anonymity (we are happy for peer-review to remain anonymous, but the rewriting leads to incomprehensible comments); and, as proposed in the Nature report, for applicants to be able to attend referees' meetings to answer questions and defend their grants.

Daniel R. Dietrich, Bettina C. Hitzfeld Department of Environmental Toxicology, University of Konstanz, PO Box 5560 -X918, D-78457 Konstanz, Germany

Nature replies - The Nature report states explicitly that the DFG reviewing process averages five to six months. The complaints discussed in the article concern the outliers to this average applications in new, interdisciplinary, not traditional, areas of research. 